\title{
Análise da construção narrativa seriada em charmed
}

\section{Analysis of serial narrative construction in charmed}

DOI: 10.46814/lajdv3n4-061

Recebimento dos originais: 01/05/2021

Aceitação para publicação: 31/06/2021

Fernanda Marques Granato

Doutorado em Literatura e Crítica Literária pela PUC-SP

Instituição atual: -

Endereço: Rua Correia de Lemos, 536, apto 111, 04140-000

E-mail: femarquesgranato@gmail.com

Elisabete Alfeld Rodrigues

Doutorado em Comunicação e Semiótica pela PUC-SP

Instituição atual: PUC-SP

Endereço: Rua Monte Alegre, 984

E-mail: ealfeld@uol.com.br

\section{RESUMO}

A ficção serializada é um aspecto importante da produção televisual contemporânea, é um tipo de formato que se apropria de recursos advindos da literatura, do folhetim e das novelas transmitidas por meio do rádio. Esse modelo narrativo migrou para a televisão e adquiriu características próprias. Como exemplo de narrativa seriada televisual, tem- se a série de TV norte americana Charmed, objeto de estudo da pesquisa realizada. O objetivo principal da pesquisa consistiu em analisar como a narrativa seriada foi construída, com destaque para a criação da trama que permeada de recursos fantásticos foi a estratégia utilizada para garantir os índices de audiência.

Palavras-chave: narrativa seriada, universo ficcional, narrativa fantástica.

\section{ABSTRACT}

Serialized fiction is an important aspect of contemporary television production; it is a type of format that appropriates resources from literature, serials and soap operas transmitted by radio. This narrative model migrated to television and acquired its own characteristics. As an example of television serialized narrative, we have the North American TV series Charmed, object of study of the research conducted. The main objective of the research was to analyze how the serialized narrative was constructed, with emphasis on the creation of the plot that, permeated by fantastic resources, was the strategy used to guarantee the audience ratings.

Keywords: serialized narrative, fictional universe, fantastic narrative.

\section{APRESENTAÇÃO DO SERIADO}

A pesquisa realizada teve como proposta o estudo da construção da narrativa ficcional seriada intitulada Charmed, lançado no ano de 1998 e transmitido na televisão norte americana até o ano de 2006. A televisão a cabo brasileira também transmitiu a série e ainda hoje retransmite os episódios. 
Criado por Constance M. Burge, o seriado narra a história de três irmãs, Prudence, Piper e Phoebe Halliwell que na vida adulta descobrem que são bruxas. Prudence tem o poder de mover os objetos com a mente, Piper pode congelar e acelerar as partículas e Phoebe é capaz de ter premonições e de levitar. Tais poderes devem ser usados na luta do bem contra o mal - missão que costuma entrar em conflito com suas vidas pessoais e profissionais.

Os poderes herdados pelas irmãs tiveram origem em Melinda Warren, que viveu na Idade Média e que era dotada dos três poderes partilhadospelas irmãs: congelar o tempo, mover os objetos com a mente e ter premonições. Esses poderes foram passados de geração em geração pelo lado feminino da família, chegando na avó das irmãs, que as criou, na mãe delas, que morreu em um enfrentamento com um demônio e, finalmente, nas próprias protagonistas, que atingem seu ápice com a reunião das três. O pai das encantadas (posição que elas representam no mundo mágico), Victor Bennet, as deixou após a morte da mãe, por discordar da posição da avócom relação a criação das meninas em meio à magia.

Paige Matthews é uma das encantadas que é descoberta apenas no início da quarta temporada, com a morte de Prue e a necessidade de reconstituir a tríade. Paige é fruto da união de Patty, mãe das demais encantadas, e o seu anjo da guarda, sendo portanto dotada dos poderes provenientes de ambas condições. Os anjos e anciãos (autoridades do bem que criam as regras e formam a moral do lado benfeitor do mundo mágico) tem a capacidade de "orbitar", ou seja, se desmaterializar com luzes azuisque brilham e se materializar em um novo local, transportando o corpo inteiro em um segundo. Os demônios, por outro lado, desaparecem "piscando", ou seja, na velocidade de um fechar e reabrir de olhos. Leo Wyatt, anjo das encantadas e futuro marido e pai dos filhos de Piper, se torna ancião, avatar (tipo de ser mágico que acredita na criação de um mundo além do bem e do mal) e finalmente mortal.

\section{METODOLOGIA}

No início da pesquisa, foram selecionados 12 episódios da série Charmed para a análise. Os episódios foram escolhidos por mostrarem a evolução da narrativa ao longo da série, os diversos equilíbrios edesequilíbrios, os conflitos presentes nos mais diversos momentos da série e as incursões do fantástico na narrativa que traz o mundo histórico como panode fundo para sua compreensão. A análise dos episódios foi caracterizadapor uma parte descritiva e uma parte temática, que traz a mensagem da narrativa desenvolvida no episódio em questão, o ensinamento que toda narrativa carrega. Os elementos fantásticos foram ilustrados com imagens da série e foram analisados à luz dos conceitos de Tzvetan Todorov. 


\section{SÍNTESE DA ANÁLISE}

A análise dos episódios selecionados da série Charmed revela osseguintes elementos comuns: as irmãs enfrentam demônios com seus respectivos poderes, sendo que alguns demônios exigem que o poder das três seja utilizado para que eles sejam destruídos; Piper, com seu poder, congela e explode os demônios; Phoebe, com a sua capacidade de ver o futuro e acessar a memória do passado, é capaz de identificar o que acontecerá a que pessoa, assim como o que o demônio que enfrentarão já realizou; as três irmãs preparam poções que são dotadas de diferentesefeitos, para serem utilizadas no combate contra os demônios; Prue ajuda as irmãs com seu poder de mover os objetos com a mente, assumindo a liderança do trio diante dos demônios e nos momentos de planejamento; Paige, também dotada do poder de Prue, auxilia dessa forma e é capaz de orbitar ela mesma ou outra pessoa para o local que deseja, o que pode ampliar as possibilidades de salvar a pessoa inocente envolvida.

Em todos os episódios, os demônios desejam desarmar as irmãsretirando os poderes das encantadas e tomando posse deles, assim como obtendo o controle e o reconhecimento do livro das sombras, livro esse que reconhece quem o manuseia e se o indivíduo é do grupo do bem ou do mal, protegendo-se dos demônios. Entretanto, as nuances dessa questãoaparecem nos diferentes demônios, nos diferentes poderes que eles possuem, nos diversos planos que são elaborados para conseguir afastar as irmãs do livro, conseguir seus poderes, obter acesso ao primogênito de Piper para torná-lo um ser do mal.

As histórias que são desenvolvidas durante a série intercalam os acontecimentos do mundo histórico com os eventos do universo ficcional, construindo a narrativa sempre com base na relação fraternal que lhe deu início e na herança mágica que a família lhes concedeu. Cada narrativa é pensada no mundo histórico, com seus personagens e ambientes, e inserida na lógica do universo ficcional, com seus acontecimentos fantásticos vindos àsuperfície (ECO, 1994).

Entretanto, todo episódio tem momentos que se passam em ambientes do mundo fíccional e outros instantes que se passam em lugares do mundo histórico, ambos são fundamentais para a construção e compreensão da trama. Afinal, o universo ficcional tem o mundo real como pano de fundo, conforme a conceituação de Eco (1994) e é necessário quese compreenda o funcionamento do mundo histórico para que se adentre o mundo ficcional, pois tudo aquilo que nele não se diferencia do mundo real, segue a mesma lógica de funcionamento.

No episódio "Malícia no País das Maravilhas", por exemplo, os adolescentes desaparecidos que, ao retornarem, estão confusos e desorientados, dizendo frases sem sentido, não são vistos pelos membros domundo histórico como tendo sido capturados e atacados por demônios. Os policias nas investigações e os jornalistas nas transmissões da imprensa apresentam os fatos como obra de algum criminoso comum, como um sequestrador ou pedófilo. 
Porém, as irmãs são conhecedoras do viés demoníaco por trás dessa situação e vão ao encontro das respostas com a ajuda de Billie, salvando os jovens sem que os cidadãos comuns saibam da verdade. A característica fundamental do fantástico, de acordo com Todorov (2003), a hesitação diantede um acontecimento sobrenatural é resolvida do ponto de vista das irmãs e de todos os personagens pertencentes ao mundo mágico, que escolhem a resposta que se encaminha para o maravilhoso, ou seja, explicam os eventossobrenaturais com outras leis naturais que não se enquadram no mundo histórico, leis essas criadas no universo ficcional que discorrem sobre ofantástico e suas vertentes.

Ao longo da série, em diversos episódios, é visível a problemática de que não é possível para as irmãs terem uma vida normal por serem dotadas desses poderes e desse destino. Há expectativa dos Anciãos e dos outros membros do lado do bem do mundo mágico e as irmãs não podem atrasar o salvamento, situação que as leva ao sacrifício de suas vidas pessoais e desejos comuns, como o de ter uma família, ter vida social, ter um emprego comum e outros mais.

O fantástico, segundo Todorov (2003), aparece na hesitação de cada cidadão comum que se depara com o universo ficcional, na hesitação das irmãs quando descobrem o fato de serem bruxas, nos poderes das irmãs quecontrariam as leis do mundo histórico, nos poderes dos demônios que, se considerados pelo leitor empírico conceituado por Umberto Eco (1994), seriam impossíveis. No episódio que inicia a série, o fantástico se insinuacom o caso das moças que são assassinadas pelo namorado de Piper. O inspetor Andy Trudeau é capturado pela hesitação provocada pela possibilidade do caso ter origens sobrenaturais. Trudeau considera a possibilidade de o assassino ser um demônio e dele ter matado as moças porelas serem bruxas e por ele desejar possuir seus poderes. Entretanto, seu parceiro na investigação, o detetive Darryl discorda de sua abordagem e segue as leis do mundo histórico, explicando os eventos sobrenaturais racionalmente. Darryl, com sua escolha, pavimenta o caminho do gênero estranho, que explica os eventos sobrenaturais com uma lógica racional. Trudeau, conforme Todorov (2003) e Eco (1994), ao se aproximar do gênero maravilhoso e das novas leis por ele criadas, diminui o espaço entre ouniverso ficcional e o mundo histórico e se avizinha das irmãs, partilhando do segredo e ajudando-as quando possível. Quando Andy morre, Darryl passa afazer a conexão entre um universo e outro.

No primeiro episódio, “Algo mágico pode acontecer", vemos como a construção da trama é trabalhada, e como o fantástico se entrelaça com o mundo histórico. O episódio se inicia com a caracterização do relacionamentode Piper e Prue enquanto irmãs, deixando que o espectador entreveja um início de conflito entre Prue e Phoebe, ainda que Phoebe ainda não tenha sido apresentada ao espectador. Depois de decorrido certo tempo, Phoebe chega a casa e discute com Prue por conta de memórias de ex-namorados. Piper, em uma tentativa de apaziguar os ânimos, oferece um jantar caseiro e é rejeitada. Essa escolha para o começo da narrativa já indica um ponto crucial que perpassará toda 
a série: os relacionamentos pautam a narrativa, auxiliando a sua construção e entrelaçando a temática familiar do mundo histórico com a sobrenatural do universo ficcional.

Retomando o pensamento de Walter Benjamin (1992), o ato de narrar tem origem na experiência do próprio narrador e na experiência a ele relatada pela tradição oral. Na narrativa construída em Charmed, a função literária do narrador é exercida pelas irmãs, portanto, a perspectiva das encantadas e a experiência delas é a que forma a narrativa, nutrindo-a com significado,fazendo-a ser compartilhada com os espectadores. As vivências das irmãs nouniverso ficcional e no mundo histórico compõem a narrativa conforme elas ocorrem, ou seja, o tempo da narrativa também é ditado pelas experiências das encantadas. A narrativa pode ser ambientada na casa das encantadas, na qual a maior parte do planejamento, preparo de poções e enfrentamento ocorrem; no P3 (o nome se refere à Prue, Piper e Phoebe, e ao poder das três), discoteca de Piper, à qual recebe as encantadas após um combate; no Bay Mirror, jornal no qual Phoebe trabalha; na Escola de Magia, que foi dirigida por Leo por um período de tempo; no restaurante Quake, onde Piper trabalhou na primeira temporada; na casa de leilões ou no museu onde Prue trabalhou; no escritório no qual Paige trabalhou como assistente social.

Considerando a teoria de Eco (1994), o universo ficcional da narrativa de Charmed tem o mundo histórico como pano de fundo e exige o conhecimento do funcionamento desse mundo. A narrativa exige a suspensão da descrença e a aceitação do acordo ficcional proposto no primeiro episódio para que a fruição da narrativa seja completa. $\mathrm{O}$ espectadordeve tentar participar como leitor de segundo nível, desvendando o não dito epercebendo o implícito.

Todorov (2003) nos traz a questão do fantástico, questão essa largamente abordada em Charmed. A hesitação, a presença de acontecimentos que podem ser explicados pela lógica racional, abrindo margem para o gênero estranho, ou explicado por outra lógica própria do sobrenatural, deixando o espaço desimpedido para o gênero maravilhoso. A função social do fantástico é claramente percebida na condição possuída pelas irmãs, a condição de bruxas, e pela condição daqueles que as enfrentam, os demônios. A colocação da questão nesses termos exclui o ser humano, o cidadão comum da feitura de maus atos, imbuído de má índole oumau caráter. Essa visão se assemelha à noção do senso comum de que o mal se encontra nos seres maus, e não em todos os seres. A série aborda diversos temas que são tidos como tabus e que podem ser colocados em termos mais leves quando são designados a outros personagens.

De acordo com Machado (2000), nas narrativas seriadas, elementos e personagens entram em contato com o repertório do espectador, formando

um estilo que só é percebido pela repetição da relação estabelecida entre elementos conhecidos e o conhecimento prévio que o espectador traz. No caso de Charmed, os personagens que compõem a 
narrativa são claramente divididos em categorias de bem e mal, separação que encontra semelhança no pensamento do senso comum, pensamento estereotipado com o qual o espectador pode estabelecer relação.

Outro aspecto a ser destacado é a sua formatação (PALLOTTINI,1998): o seriado traz uma história completa no episódio que está inserido em um contexto maior, podendo ser acompanhado por espectadores ocasionais. Em Charmed, cada episódio apresenta uma situação de conflito claramente estabelecida pela presença de um novo demônio, que é identificado, estudado e combatido pelas irmãs de forma específica em cada episódio.Isso constitui um ciclo de começo, meio e fim que se apresenta em cada segmento e que compõe o contexto maior da história das irmãs, que é composto por esses vários embates e diversas narrativas menores.

\section{CONSIDERAÇÕES FINAIS}

A narrativa seriada construída em Charmed é desenvolvida tendo por base a relação entre as três irmãs, Prue, Piper e Phoebe, e as vivências que elas compartilham. Os poderes que as irmãs herdaram são datados de uma época na qual os conhecimentos eram transmitidos pela tradição oral, sabedoria essa carregada de autoridade. Os saberes acumulados ao longo das gerações foram compilados para formar o livro das Sombras, etapa construtiva da narrativa que configura a preocupação com um leitor, o qual deve trazer os conhecimentos do mundo histórico, porém deve estar dispostoa suspender a descrença para aceitar que poções são capazes de destruir demônios e que existem seres que desafiam a noção corrente de tempo, podendo congelar ou retroceder a linha do tempo. O costume arraigado foi fortalecido pela família que, potencializada pela sabedoria, pelos poderes herdados e pela tríade formada pelas irmãs, pode se libertar dos limites do mundo histórico e das leis que o explicam e ir figurar em outro mundo, cativo do gênero maravilhoso, no qual outras leis são criadas para explicar um mundo além da realidade observada. 


\section{REFERÊNCIAS}

\section{REFERENCIAS}

ARONCHI de SOUZA, José Carlos. Gêneros e formatos na televisãobrasileira. São Paulo: Summus, 2004.

BENJAMIN, Walter. O narrador. In: Sobre arte, técnica, linguagem e política.Editora Relógio D’água, 1992.

CARLOS, Cássio Starling. Em tempo real: Lost, 24 horas, Sex and the Citye o impacto das novas séries de TV. São Paulo: Alameda, 2006.

ECO, Umberto. Seis passeios pelos bosques da ficção. São Paulo:Companhia das Letras, 1994.

MACHADO, Arlindo. A televisão levada a sério.- São Paulo: Editora SENACSão Paulo, 2000.

PALLOTTINI, Renata. Dramaturgia de televisão. Editora Moderna, 1998. TODOROV, Tzvetan. A narrativa fantástica. In: As estruturas narrativas.Editora Perspectiva, 2003. 